\title{
Topical Tranexamic Acid Does Not Affect Electrophysiologic or Neurovascular Sciatic Nerve Markers in an Animal Model
}

\author{
Ran Schwarzkopf MD, MSc, Phuc Dang MD, \\ Michele Luu, Tahseen Mozaffar MD, \\ Ranjan Gupta MD
}

Received: 29 April 2014/ Accepted: 3 December 2014/Published online: 6 January 2015

(C) The Association of Bone and Joint Surgeons $\mathbb{R} 2015$

\begin{abstract}
Background Tranexamic acid is a safe and effective antifibrinolytic agent used systemically and topically to reduce blood loss and transfusion rate in patients having TKA or THA. As the hip does not have a defined capsule, topical application of tranexamic acid may entirely envelop the sciatic nerve during THA. Accidental application of tranexamic acid onto the spinal cord in spinal anesthesia has been shown to produce seizures; therefore, we sought to investigate if topical application of tranexamic acid on the sciatic nerve has a deleterious effect.
\end{abstract}

\footnotetext{
Each author certifies that he or she, or a member of his or her immediate family, has no funding or commercial associations (eg, consultancies, stock ownership, equity interest, patent/licensing arrangements, etc) that might pose a conflict of interest in connection with the submitted article.

All ICMJE Conflict of Interest Forms for authors and Clinical Orthopaedics and Related Research ${ }^{\mathbb{B}}$ editors and board members are on file with the publication and can be viewed on request.

Each author certifies that his or her institution approved the animal protocol for this investigation and that all investigations were conducted in conformity with ethical principles of research. This work was performed at the Peripheral Nerve Research Laboratory, University of California, Irvine, Irvine, CA, USA.
}

R. Schwarzkopf, P. Dang, R. Gupta ( $\square)$

Department of Orthopaedic Surgery, University of California, Irvine, 101 The City Drive S, Pavillion III, Orange, CA 92868, USA

e-mail: ranjang@uci.edu

\section{Luu}

Peripheral Nerve Research Laboratory, University of California, Irvine, Irvine, CA, USA

T. Mozaffar

Department of Neurology, University of California, Irvine,

Orange, CA, USA
Questions/purposes We explored whether there were any short- or long-term alterations in (1) electrophysiologic measures, (2) macrophage recruitment, or (3) blood-nerve barrier permeability. Our hypothesis was that local application of tranexamic acid would have a transient effect or no effect on histologic features and function of the sciatic nerve.

Methods We used a rat protocol to model sciatic nerve exposure in THA to determine the effects of tranexamic acid on neural histologic features and function. We evaluated 35 rats by the dorsal gluteal splitting approach to expose the sciatic nerve for topical use of control and tranexamic acid. We evaluated EMG changes (distal latency, amplitude, nerve conduction velocity), histologic signs of nerve injury via macrophage recruitment, and changes in blood-nerve barrier permeability at early (4 days) and late (1 month) times after surgery, after application of subtherapeutic $(1 \mathrm{mg} / \mathrm{kg}$ body weight [1.6 mg]), therapeutic $(10 \mathrm{mg} / \mathrm{kg}[16 \mathrm{mg}])$, and supratherapeutic $\quad(100 \mathrm{mg} / \mathrm{kg} \quad[160 \mathrm{mg}])$ concentrations of tranexamic acid. Differences in blood-nerve barrier permeability, macrophage recruitment, and EMG between normal and tranexamic acid-treated nerves were calculated using one-way ANOVA, with Newman-Keuls post hoc analyses, at each time. A post hoc power calculation showed that with the numbers available, we had $16 \%$ power to detect a 50\% difference in EMG changes between the control, $1 \mathrm{mg} / \mathrm{kg}$ group, $10 \mathrm{mg} / \mathrm{kg}$ group, and $100 \mathrm{mg} / \mathrm{kg}$ group.

Results At the early and late times, with the numbers available, there were no differences in EMG except for distal latency at 4 days, macrophage recruitment, or changes in blood-nerve barrier between control rats and those with tranexamic acid-treated nerves. The distal latency in the $1 \mathrm{mg}$ tranexamic acid-treated animals at 
4 days was $1.06 \pm 0.15 \mathrm{~ms}(\mathrm{p}=0.0036$ versus all other groups, 95\% CI, 0.89-1.25), whereas the distal latencies in the control, the $10 \mathrm{mg} / \mathrm{kg}$, and $100 \mathrm{mg} / \mathrm{kg}$ tranexamic acidtreated animals were $0.83 \pm 0.11,0.89 \pm 0.05$, and $0.87 \pm 0.13$, respectively. Distal latencies were not increased in any of the groups at 1 month with the numbers available $(0.81 \pm 0.10,0.89 \pm 0.03,0.81 \pm 0.06$, and $0.83 \pm 0.08 \mathrm{~ms}$, respectively, for controls; $1 \mathrm{mg} / \mathrm{kg}$, $10 \mathrm{mg} / \mathrm{kg}$, and $100 \mathrm{mg} / \mathrm{kg}$ for the tranexamic acid-treated groups).

Conclusion In our in vivo rat model study, tranexamic acid did not appear to have any clinically relevant effect on the sciatic nerve resulting from topical administration up to 1 month. However, because our statistical power was low, these data should be considered hypothesis-generating pilot data for larger, more-definitive studies.

Clinical Relevance Topical tranexamic acid is effective in decreasing patient blood loss during THA, and results from our in vivo rat model study suggest there may be no electrophysiologic and histologic effects on the sciatic nerve, with the numbers available, up to 1 month.

\section{Introduction}

Studies have shown that tranexamic acid is an effective antifibrinolytic agent that may be used systemically in patients undergoing TKA or THA $[1,2,4,9,14,19,26,33$, 37, 39]. Tranexamic acid (Cyklokapron ${ }^{\circledR}$, Pfizer Inc, New York, NY, USA), a synthetic inhibitor of fibrinolysis, blocks the lysine-binding site of plasminogen and thereby serves to competitively inhibit activation of plasminogen to plasmin [3]. Studies support systemic and topical use of tranexamic acid for reducing blood loss and the need for blood transfusions without an apparent increase in the risk of deep vein thrombosis (DVT) or pulmonary embolism (PE) during arthroplasty [1, 2, 8, 11, 30-32, 35-37].

Despite the reported benefits of tranexamic acid, incidences of DVT and PE have been reported after the use of tranexamic acid [18, 29]. Furthermore, accidental use of tranexamic acid in spinal anesthesia has been associated with convulsions in patients [5, 23]. Direct application of tranexamic acid in a rat spinal cord model showed it to induce seizures [30]. In addition to seizures, there are some clinical contraindications and precautions to intravenous administration of tranexamic acid, including active intravascular clotting, subarachnoid hemorrhage, previous thromboembolic event, and renal failure [34].

Owing to the adverse reactions associated with systemic administration of tranexamic acid, there is increasing interest in topical use of tranexamic acid to directly target the source of bleeding. With lower systemic absorption associated with topical use of tranexamic acid, there is a theoretic lower risk of thromboembolic complications, which allows for the use of tranexamic acid when systemic administration is contraindicated [35]. Although tranexamic acid has been applied topically intraarticularly in the knee during TKA and in the hip during THA with good efficacy and decreased risk of thromboembolic events $[1,15,20,22,31]$, to our knowledge, no study to date has rigorously examined the effects of direct application of tranexamic acid on morphologic features and function of the sciatic nerve. As the hip does not have a defined capsule like the knee, topical use of tranexamic acid during THA bathes the sciatic nerve with the agent.

We therefore investigated the effects of tranexamic acid using an in vivo animal model of the sciatic nerve. As tranexamic acid affects the clotting cascade, we explored if there were any short- or long-term alterations in (1) electrophysiologic measures, (2) macrophage recruitment, or (3) blood-nerve barrier permeability, our hypothesis being that local application of tranexamic acid would have a transient effect or no effect on histologic features and function of the sciatic nerve.

\section{Methods}

To determine if tranexamic acid has any short- or longterm local and systemic effects when placed topically adjacent to the sciatic nerve, we used a rat model that simulated sciatic nerve exposure to tranexamic acid that occurs in patients undergoing THA. The sciatic nerve was examined previously for any functional nerve deficits via electrodiagnostic studies [21], histologic signs of nerve injury via macrophage recruitment [17], and changes in the blood-nerve barrier using Evans blue albumin diffusion [16].

\section{Surgical Procedure}

Thirty-five male, 250-mg Sprague-Dawley rats were used in our study (Charles River Laboratories, San Diego, CA, USA). Animal surgeries were approved by the institutional Animal Care and Use Committee of the University of California, Irvine, and the study was approved by our institutional review board.

All rats were anesthetized with an intraperitoneal injection of ketamine and xylazine at 80 to $100 \mathrm{mg} / \mathrm{kg}$ and 5 to $10 \mathrm{mg} / \mathrm{kg}$ [17]. A dorsal gluteal-splitting approach was used on both rat hind limbs to directly expose the sciatic nerves in each animal, as would be performed during routine THA. One milliliter of normal saline solution 
containing three different concentrations (subtherapeutic, $1 \mathrm{mg} / \mathrm{kg}$; therapeutic, $10 \mathrm{mg} / \mathrm{kg}$; or supratherapeutic, $100 \mathrm{mg} / \mathrm{kg}$ ) of tranexamic acid was placed topically in the right hind leg near the sciatic nerve. Ten milligrams per kilogram was selected as a therapeutic concentration as those used in TKA and THA range from $500 \mathrm{mg}$ to $3 \mathrm{~g}$ for an adult human whose average weight is approximately $70 \mathrm{~kg}$ to $85 \mathrm{~kg}[12,20]$. One milliliter of normal saline control was placed in the left hind leg near the sciatic nerve as a matched control. To limit variability, all surgical procedures were performed by the senior author (RG). None of the study rats died from our initial surgery and all remained ambulatory without any gross deficit. All rats completed the study protocol.

Animals were euthanized by an anesthetic overdose [17]. For characterization of the blood-nerve barrier integrity and macrophage recruitment, animals were sacrificed at two different times after tranexamic acid application: 4 days ( $\mathrm{n}=5,1 \mathrm{mg} / \mathrm{kg} ; \mathrm{n}=5,10 \mathrm{mg} / \mathrm{kg} ; \mathrm{n}=5,100 \mathrm{mg} / \mathrm{kg}$; and $\mathrm{n}=3$, no tranexamic acid as negative controls); and 1 month $(\mathrm{n}=5,1 \mathrm{mg} / \mathrm{kg} ; \mathrm{n}=5,10 \mathrm{mg} / \mathrm{kg} ; \mathrm{n}=5$, $100 \mathrm{mg} / \mathrm{kg}$; and $\mathrm{n}=2$, no tranexamic acid as negative controls). Experimental (right sciatic) and saline-injected control (left sciatic) nerves were harvested from each animal.

\section{EMG}

Before animal sacrifice, EMG was performed in vivo on all animals by a qualified board-certified neurologist (TM), to determine distal latency, amplitude, and nerve conduction velocity [10]. Motor conduction studies in the sciatic-tibial fibers were performed by stimulating the sciatic nerve at the sciatic notch and popliteal region using a monopolar needle electrode. The reference needle-stimulating electrode was placed in the ipsilateral lumbar paraspinal muscle. The M-wave (compound motor action potential) from the peroneal-innervated ankle dorsiflexor muscle (tibialis anterior) was recorded by placing a subdermal electroencephalogram needle electrode in the muscle approximately $3 \mathrm{~mm}$ above the ankle. The distal latency, amplitude of the response, and nerve conduction velocity were computed. The referencerecording electrode was inserted in the plantar aspect of the foot. All neurophysiologic recordings were obtained using a Cadwell Sierra ${ }^{\mathrm{B}}$ LT machine (Cadwell Laboratories, Kennewick, WA, USA).

\section{Tissue Processing}

After harvest, sciatic nerves were preserved in $4 \%$ paraformaldehyde solution at $4{ }^{\circ} \mathrm{C}$ overnight and then cryoprotected in serial dilutions of sucrose for 3 hours each
(10\%, 20\%, and $30 \%$ sucrose in $0.1 \mathrm{~mol} / \mathrm{L}$ phosphate buffered saline [PBS]). Nerve samples were frozen, embedded in a 1:1 mixture of optimal cutting temperature compound (Sakura Finetek, Torrance, CA, USA) and Aqua Mount ${ }^{\circledR}$ (Lerner Laboratories, Pittsburgh, PA, USA). Specimens were cut in $15-\mu \mathrm{m}$ - thick cross sections with a cryostat, mounted on poly-L-lysine-coated glass slides (Fisher Scientific, Pittsburgh, PA, USA), and stored at $-80{ }^{\circ} \mathrm{C}$ until testing.

\section{Immunohistochemistry}

Immunohistochemistry was performed on the sciatic nerve cross sections to detect ED1-IR, a marker specific for activated macrophages [17]. Positive control samples of the spleen and liver were used to detail localization of hematogenously derived macrophages. Frozen sections of the nerve, spleen, and liver were fixed in paraformaldehyde and immersed in $0.1 \%$ Triton $^{\circledR}$ X-100 in PBS (Thermo Fisher Scientific, NJ, USA). Nonspecific binding was blocked with $10 \%$ goat antibodies or bovine serum albumin. Sections were incubated with mouse anti-rat ED1-IR (1:300; Chemicon, Temecula, CA, USA) overnight at $4{ }^{\circ} \mathrm{C}$. Control sections were incubated without exposure to primary antibodies. After thorough washes with PBS, slides were incubated in fluorescein isothiocyanate-labeled goat anti-mouse immunoglobulin (IgG, 1:500; Chemicon) for 1 hour. After washes in PBS, slides were counterstained and mounted with Vectashield ${ }^{\circledR}$ antifade solution containing 4',6-diamidino-2-phenylindole (DAPI; Vector Laboratories, Burlingame, CA, USA) and viewed with an Olympus fluorescent microscope (Olympus Corporation, Center Valley, PA, USA) equipped with PathVysion ${ }^{\circledR}$ software (Applied Imaging, San Jose, CA, USA).

Immunohistochemical analysis was performed to identify endothelial cells lining the lumen of microvessels in the nerve sections. Frozen sections were immersed in $4 \%$ paraformaldehyde and then blocked with $10 \%$ normal goat serum and $0.1 \%$ Triton $^{\circledR}$ X-100 in PBS for 1 hour. The sections were incubated overnight at $4{ }^{\circ} \mathrm{C}$ with anti-rat endothelial cell antigen-1 (anti-RECA 1; 1:200; Serotec, Bicester, UK). After washes with PBS, the sections were incubated in fluorescein-conjugated goat anti-mouse IgG (1:200) for 1 hour. Slides were washed with PBS, stained with DAPI, and observed with an Olympus IX-71 fluorescence microscope.

Macrophage Recruitment

Using an Olympus IX-71 microscope equipped with SlideBook $^{\mathrm{TM}} 4.1$ (Intelligent Imaging Innovations, Denver, 
$\mathrm{CO}$, USA), the total numbers of ED1-IR stained cells were counted on specimens harvested at 4 days and 1 month after surgery. Only labeled cells with visible nuclei were counted. Macrophage numbers were counted under $40 \times$ per $100 \mu \mathrm{m} \times 100-\mu \mathrm{m}$ section. For each nerve, multiple sections were prepared. Three to five sections were selected for analysis, each with intact axonal structural integrity. A $100 \mu \mathrm{m} \times 100 \mu \mathrm{m}$ section then was selected randomly to account for variability in and between specimens.

\section{Evans Blue Albumin}

Blood-nerve barrier permeability (integrity) was evaluated using Evans Blue albumin, a solution of 5\% bovine serum albumin (Sigma-Aldrich, St Louis, MO, USA) mixed with $1 \%$ Evans Blue dye (Sigma-Aldrich) in sterile distilled water and filtered through a G-25Medium Sephadex ${ }^{\circledR}$ column (Sigma-Aldrich, St Louis, MO, USA). In accordance with previously described methods [16, 24], $1 \mathrm{~mL}$ Evans Blue albumin per $100 \mathrm{~g}$ body weight was injected intravenously, under anesthesia, and allowed to circulate for 15 minutes before the sciatic nerves were harvested and prepared as described. Before evaluation, nerve cross sections were counterstained with DAPI to localize cell nuclei.

\section{Quantification of Changes in Blood-nerve Barrier Permeability}

As reported [16], functionality of the blood-nerve barrier was evaluated by comparing the fluorescence of the Evans Blue albumin in the neural microvasculature with surrounding endoneurium. ImageJ (National Institutes of Health, Bethesda, MD, USA) was used to determine the average optical density of five random $10-\times-10$ pixel areas (approximately $4 \mu \mathrm{m}^{2}$ ) in a randomly selected microvessel and five random $10-\times-10$ pixel areas from the surrounding endoneurium. The comparative ratio of intensity in a blood vessel to endoneurium was calculated by dividing the average intensity of the five blood vessel optical density measurements by the average optical density of the five endoneurial measurements (Fig. 1).

\section{Statistical Analysis}

All statistical analyses were performed using Prism 5 (GraphPad, San Diego, CA, USA). Data are presented as the mean and SD. Differences in Evans Blue albumin optical density, macrophage recruitment (ED1-IR cells), and EMG (distal latency, amplitude, nerve conduction velocity) between normal and tranexamic acid-treated

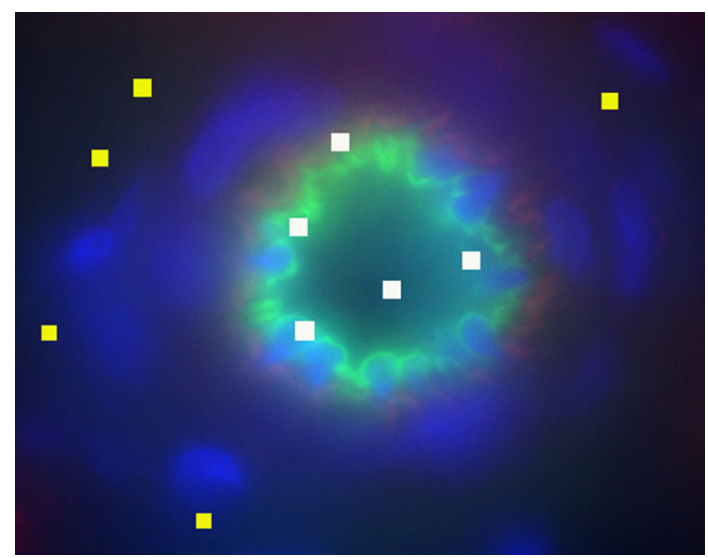

Fig. 1 An image of a blood vessel in a sciatic nerve axon shows the method of quantification of changes in blood-nerve barrier permeability. Extravasation of Evans Blue albumin is red, cell nuclei stained with DAPI are blue; anti-RECA-1 for endothelial cells is green; the black area inside the green endothelial cell layer is the lumen of a vessel, and the black area outside the green is the extracellular matrix. With ImageJ, the optical density intensity was measured by selecting five random areas in a microvessel (white squares) and five random areas from the surrounding endoneurium (yellow squares). All squares represent $10 \times 10$ pixel areas (approximately $4 \mu \mathrm{m}^{2}$ ).

nerves were calculated using one-way ANOVA, with Newman-Keuls post hoc analyses, at each time. A post hoc power calculation showed that with the numbers available, we had $16 \%$ power to detect a $50 \%$ difference in EMG changes between the control group, $1 \mathrm{mg} / \mathrm{kg}$ group, $10 \mathrm{mg} /$ $\mathrm{kg}$ group, and $100 \mathrm{mg} / \mathrm{kg}$ group.

\section{Results}

At 4 days (Fig. 2) and at 1 month (Fig. 3) after surgery, there were no differences between the control group nerves nor any of the treatment groups in terms of nerve conduction velocity or amplitude, with the numbers available (Table 1). There was an increase in distal latency in the $1 \mathrm{mg} / \mathrm{kg}$ tranexamic acid-treated group only at 4 days, but the difference did not persist at 1 month, with the numbers available. The distal latency in the $1 \mathrm{mg}$ tranexamic acidtreated animals at 4 days was $1.06 \pm 0.15 \mathrm{~ms}(\mathrm{p}=0.0036$ versus all other groups), whereas the distal latencies in the control, the $10 \mathrm{mg} / \mathrm{kg}$, and $100 \mathrm{mg} / \mathrm{kg}$ tranexamic acidtreated animals were $0.83 \pm 0.11,0.89 \pm 0.05$, and $0.87 \pm 0.13 \mathrm{~ms}$, respectively. Distal latencies were not increased in any of the groups at 1 month with the numbers available $(0.81 \pm 0.10,0.89 \pm 0.03,0.81 \pm 0.06$, and $0.83 \pm 0.08 \mathrm{~ms}$, respectively, for controls; $1 \mathrm{mg} / \mathrm{kg}$, $10 \mathrm{mg} / \mathrm{kg}$, and $100 \mathrm{mg} / \mathrm{kg}$ for the tranexamic acid-treated groups) (Table 2).

There were no differences when quantifying the amount of macrophages between treated and control rats with the 


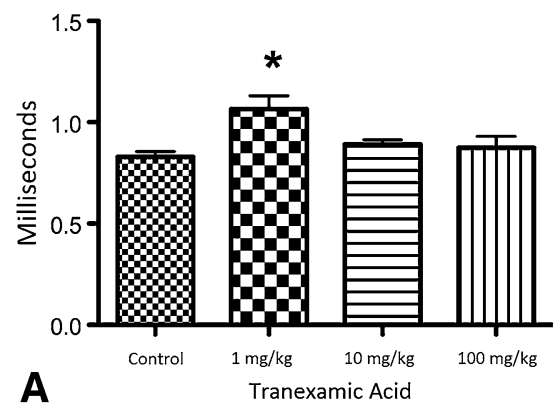

Fig. 2A-C The graphs show (A) distal latency, (B) amplitude, and (C) nerve conduction velocity of a rat sciatic nerve at 4 days. The control group $(\mathrm{n}=18)$ had the sciatic nerve exposed to saline; the $1 \mathrm{mg} / \mathrm{kg}$ group $(\mathrm{n}=5)$ had the sciatic nerve exposed to $1 \mathrm{mg} / \mathrm{kg}$
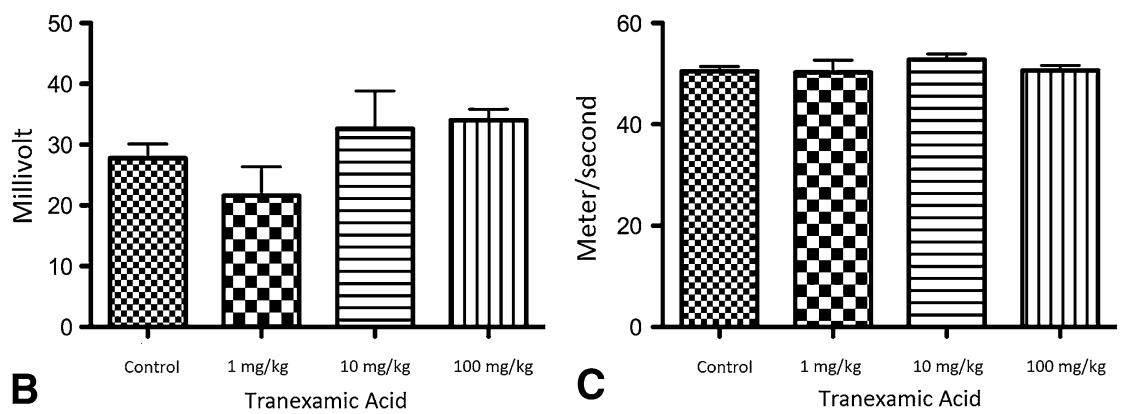

tranexamic acid; the $10 \mathrm{mg} / \mathrm{kg}$ group $(\mathrm{n}=5)$ had the sciatic nerve exposed to $10 \mathrm{mg} / \mathrm{kg}$ tranexamic acid; and the $100 \mathrm{mg} / \mathrm{kg}$ group $(\mathrm{n}=5)$ had the sciatic nerve exposed to $100 \mathrm{mg} / \mathrm{kg}$ tranexamic acid; *Significant $(\mathrm{p}=0.0036)$.

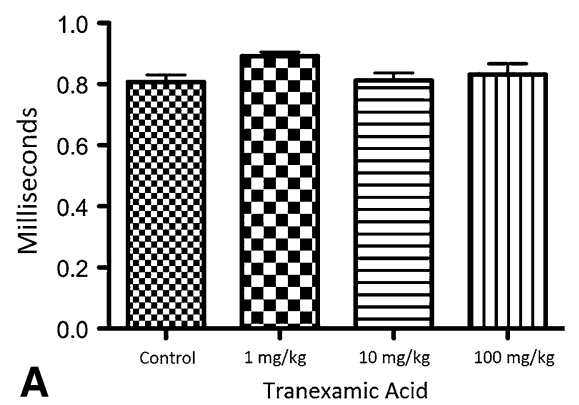

Fig. 3A-C The graphs show (A) distal latency, (B) amplitude, and (C) nerve conduction velocity of rat sciatic nerve at 1 month. Control rats $(n=17)$ were those with sciatic nerves exposed to saline. The $1 \mathrm{mg} / \mathrm{kg}$ are rats $(\mathrm{n}=5)$ whose sciatic nerve was exposed to $1 \mathrm{mg} / \mathrm{kg}$
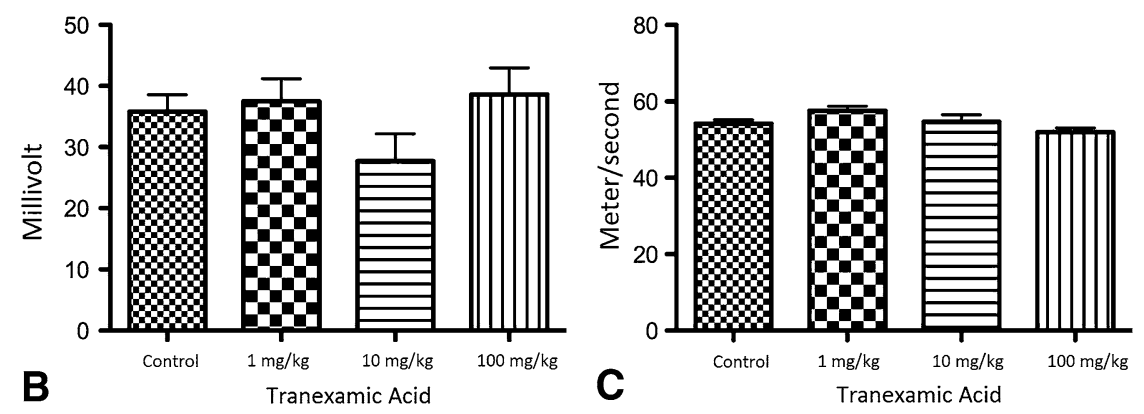

Table 1. Electrodiagnostic studies at 4 days

\begin{tabular}{llll}
\hline $\begin{array}{l}\text { Group } \\
\text { (numbers) }\end{array}$ & $\begin{array}{l}\text { Distal latency } \\
\text { (milliseconds) }\end{array}$ & $\begin{array}{l}\text { Amplitude } \\
\text { (millivolt) }\end{array}$ & $\begin{array}{l}\text { Conduction velocity } \\
\text { (meter/second) }\end{array}$ \\
\hline Control (18) & $0.83 \pm 0.11$ & $28 \pm 10$ & $50 \pm 4$ \\
$1 \mathrm{mg} / \mathrm{kg} \mathrm{(5)}$ & $1.06 \pm 0.15^{\dagger}$ & $22 \pm 10$ & $50 \pm 5$ \\
& $(\mathrm{p}=0.004)$ & & \\
$10 \mathrm{mg} / \mathrm{kg}(5)$ & $0.89 \pm 0.05$ & $33 \pm 14$ & $53 \pm 2$ \\
$100 \mathrm{mg} / \mathrm{kg}(5)$ & $0.87 \pm 0.13$ & $34 \pm 4$ & $51 \pm 2$ \\
\hline
\end{tabular}

* All values are mean and $\mathrm{SD} ;{ }^{\dagger}$ significant.

numbers available. Four days after surgery, $2.6 \pm 1.27$ macrophages were seen in the control sciatic nerve sections, $3.2 \pm 1.10$ macrophages in the $1 \mathrm{~g} / \mathrm{kg}$ tranexamic acid-treated nerve sections, $1.8 \pm 0.84$ macrophages in the $10 \mathrm{mg} / \mathrm{kg}$ tranexamic acid-treated nerve sections, and $1.8 \pm 0.84$ macrophages in the $100 \mathrm{mg} / \mathrm{kg}$ tranexamic acid-treated nerve sections $(\mathrm{p}=0.14)$ (Fig. 4). At 1 month after surgery, $2.5 \pm 0.87$ macrophages were seen in the control sciatic nerve sections, $2.2 \pm 0.84$ macrophages in the $1 \mathrm{mg} / \mathrm{kg}$ tranexamic acid-treated nerve sections, $2.2 \pm 0.84$ macrophages in the $10 \mathrm{mg} / \mathrm{kg}$ tranexamic acidtreated nerve sections, and $1.4 \pm 0.55$ macrophages in the of tranexamic acid. The $10 \mathrm{mg} / \mathrm{kg}$ are rats $(\mathrm{n}=5)$ whose sciatic nerve was exposed to $10 \mathrm{mg} / \mathrm{kg}$ of tranexamic acid. The $100 \mathrm{mg} / \mathrm{kg}$ are rats $(\mathrm{n}=5)$ whose sciatic nerve was exposed to $100 \mathrm{mg} / \mathrm{kg}$ of tranexamic acid; $p=0.38$, which did not reach significance*.
Table 2. Electrodiagnostic studies at 1 month

\begin{tabular}{llll}
\hline $\begin{array}{l}\text { Group } \\
\text { (numbers) }\end{array}$ & $\begin{array}{l}\text { Distal latency } \\
\text { (milliseconds) }\end{array}$ & $\begin{array}{l}\text { Amplitude } \\
\text { (millivolt) }\end{array}$ & $\begin{array}{l}\text { Conduction velocity } \\
\text { (meter/second) }\end{array}$ \\
\hline Control (17) & $0.81 \pm 0.1$ & $36 \pm 11$ & $54 \pm 4$ \\
$1 \mathrm{mg} / \mathrm{kg} \mathrm{(5)}$ & $0.89 \pm 0.03$ & $38 \pm 8$ & $58 \pm 3$ \\
$10 \mathrm{mg} / \mathrm{kg}(5)$ & $0.81 \pm 0.06$ & $28 \pm 10$ & $54 \pm 4$ \\
$100 \mathrm{mg} / \mathrm{kg}(5)$ & $0.83 \pm 0.08$ & $39 \pm 10$ & $52 \pm 2$ \\
\hline
\end{tabular}

All values are mean \pm SD.

$100 \mathrm{mg} / \mathrm{kg}$ tranexamic acid-treated nerve sections (p = 0.09) (Fig. 5).

No differences in leakage of Evans Blue albumin (blood-nerve barrier permeability or integrity) were observed in the control (saline) samples, in the $1 \mathrm{mg} / \mathrm{kg}$ tranexamic acid, $10 \mathrm{mg} / \mathrm{kg}$ tranexamic acid, and $100 \mathrm{mg} /$ $\mathrm{kg}$ tranexamic acid-treated nerves at 4 days or 1 month (Fig. 6) after surgery with the numbers available. At 4 days, the ratio of Evans Blue albumin leakage was $2.40 \pm 0.96$ for controls, $3.67 \pm 1.27$ for the $1 \mathrm{mg} / \mathrm{kg}$ group, $3.92 \pm 2.21$ for the $10 \mathrm{mg} / \mathrm{kg}$ group, and $3.14 \pm 1.10$ for the $100 \mathrm{mg} / \mathrm{kg}$ group $(\mathrm{p}=0.10)$. At 1 month, the ratio of leakage was $2.52 \pm 0.80$ for the 




Fig. 4A-B Macrophage recruitment quantifications at (A) 4 days and (B) 1 month using ED1-IR marker for macrophages are shown. Control rats $(\mathrm{n}=17)$ were those whose sciatic nerve was exposed to saline; $1 \mathrm{mg} / \mathrm{kg}$ rats $(\mathrm{n}=5)$ had the sciatic nerve exposed to $1 \mathrm{mg} / \mathrm{kg}$

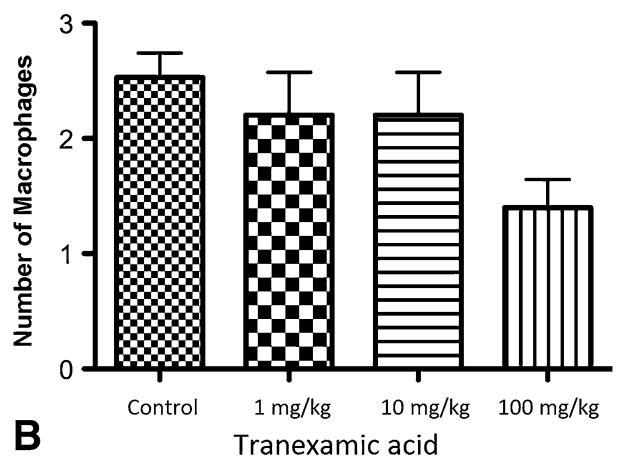

tranexamic acid; $10 \mathrm{mg} / \mathrm{kg}$ rats $(\mathrm{n}=5)$ had the sciatic nerve exposed to $10 \mathrm{mg} / \mathrm{kg}$ tranexamic acid, and $100 \mathrm{mg} / \mathrm{kg}$ rats $(\mathrm{n}=5)$ had the sciatic nerve exposed to $100 \mathrm{mg} / \mathrm{kg}$ tranexamic acid. *Significant.

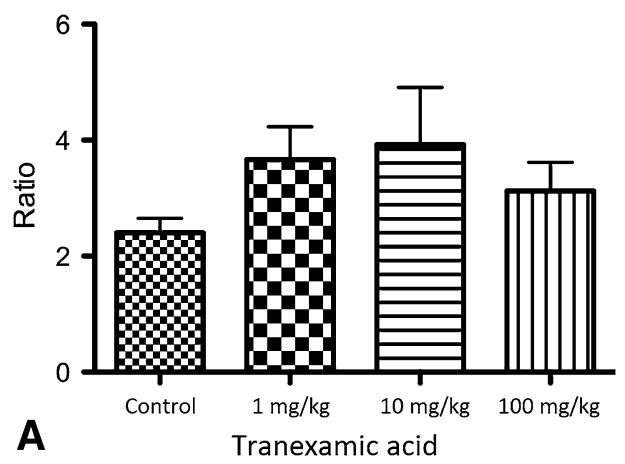

Fig. 5A-B The blood-nerve barrier integrity examinations for extravasation using Evans Blue albumin at (A) 4 days and at (B) 1 month are shown. Control rats $(n=17)$ were those whose sciatic nerve was exposed to saline; $1 \mathrm{mg} / \mathrm{kg}$ rats $(\mathrm{n}=5)$ had the sciatic

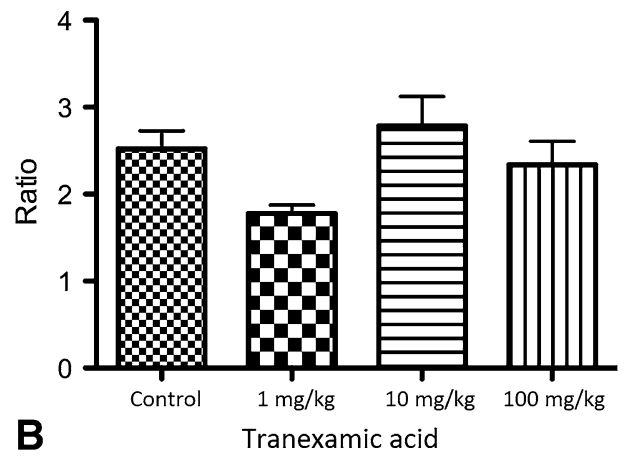

nerve exposed to $1 \mathrm{mg} / \mathrm{kg}$ tranexamic acid; $10 \mathrm{mg} / \mathrm{kg}$ rats $(\mathrm{n}=5)$ had the sciatic nerve exposed to $10 \mathrm{mg} / \mathrm{kg}$ tranexamic acid, and $100 \mathrm{mg} / \mathrm{kg}$ rats $(\mathrm{n}=5)$ had the sciatic nerve exposed to $100 \mathrm{mg} / \mathrm{kg}$ tranexamic acid. *Significant.
Fig. 6A-H The blood-nerve barrier integrity examinations using Evans Blue albumin show extravasation (red) at 4 days for the (A) control group, and (B) $1 \mathrm{mg} / \mathrm{kg}$, (C) $10 \mathrm{mg} / \mathrm{kg}$, and (D) $100 \mathrm{mg} / \mathrm{kg}$ groups. The examinations also are shown for $(\mathbf{E})$ the control group, and $(\mathbf{F}) 1 \mathrm{mg} /$ $\mathrm{kg}$, (G) $10 \mathrm{mg} / \mathrm{kg}$, and (H) $100 \mathrm{mg} / \mathrm{kg}$ groups at 1 month. Blue is stained with DAPI for cell nuclei. Green is stained with ED1-IR for endothelium. The black area inside the green endothelium is the lumen of a vessel. The black area outside the green is the extracellular matrix. The control rats $(n=17)$ had the sciatic nerve exposed to saline, the $1 \mathrm{mg} / \mathrm{kg}$ rats $(\mathrm{n}=5)$ had the sciatic nerve exposed to $1 \mathrm{mg} /$ $\mathrm{kg}$ tranexamic acid, the $10 \mathrm{mg} / \mathrm{kg}$ rats $(\mathrm{n}=5)$ had the sciatic nerve exposed to $10 \mathrm{mg} / \mathrm{kg}$ tranexamic acid, and the $100 \mathrm{mg} / \mathrm{kg}$ rats $(n=5)$ had the sciatic nerve exposed to $100 \mathrm{mg} / \mathrm{kg}$ tranexamic acid.

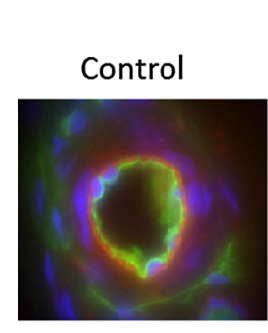

A

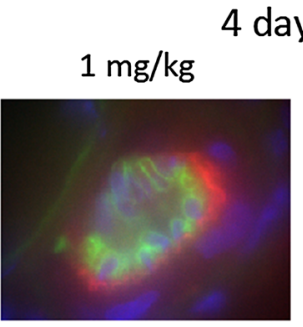

B

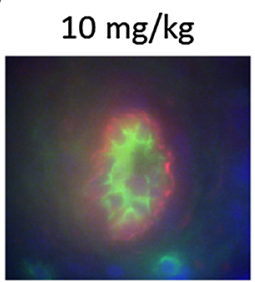

C

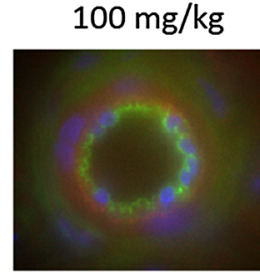

D

\section{1 month}
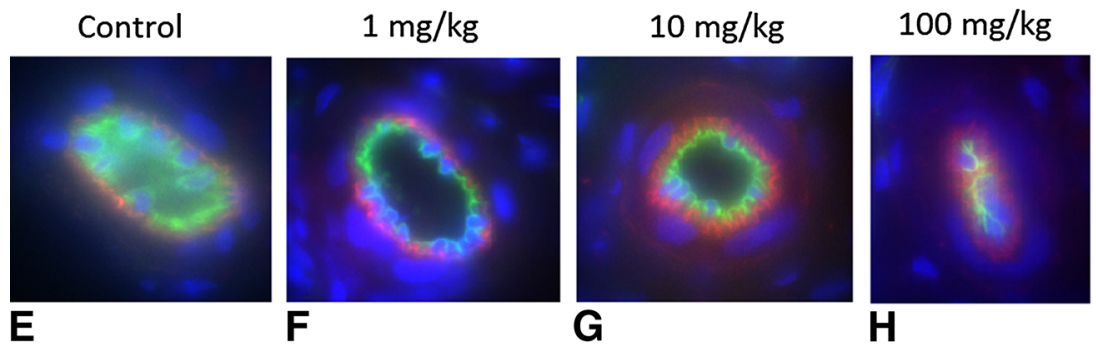
control group, $1.78 \pm 0.22$ for the $1 \mathrm{mg} / \mathrm{kg}$ group, $2.78 \pm 0.76$ for the $10 \mathrm{mg} / \mathrm{kg}$ group, and $2.34 \pm 0.60$ for the $100 \mathrm{mg} / \mathrm{kg}$ group $(\mathrm{p}=0.15)$.

\section{Discussion}

Numerous reports suggest that use of intravenous tranexamic acid is effective in reducing patient blood loss without increasing the risk of thromboembolic events in select cases of total joint arthroplasty [6, 7, 31-33, 37]. However, safety concerns have been raised [18, 29] pertaining to thromboembolic, cardiovascular, and neurologic risks with the use of tranexamic acid. In particular, seizures have been reported when tranexamic acid is accidently placed onto the spinal cord during spinal anesthesia and when directly applied to the rat spinal cord $[5,23,30]$. We therefore sought to determine whether use of tranexamic acid has an effect on histologic features and function of the sciatic nerve by evaluating EMG changes (distal latency, amplitude, nerve conduction velocity), histologic signs of nerve injury via macrophage recruitment, and changes in bloodnerve barrier permeability at early (4 days) and late (1 month) times after surgery. We found that at both times, topical application of tranexamic acid in a rat model did not appear to have any effect on histologic features and function of the sciatic nerve, with the numbers available.

Limitations of our study include the small number of animals, nonrandomization of the animals, and the limited times selected for postsurgical evaluation. Although our morphometric data appeared to approach statistical significance with our sample size and increased numbers might become statistically significant, it would not change our conclusions as there were no meaningful functional deficits with animals. In addition, post hoc statistical analysis of EMG was found to be $16 \%$, and future studies with increased numbers may detect a difference. We selected the two times owing to the short half-life of tranexamic acid and time of detectable nerve injury [16, 17, 27]. As our exposure might not entirely simulate the complex environment of a THA, there is concern for potential increased invasiveness of the procedure. As such, there is the possibility that with increased inflammation and blood flow, there might be increased drug availability to the nerve. However, as the supratherapeutic concentration in our animal model did not have an adverse effect, this should account for the possibility of increased absorption of tranexamic acid with an actual THA. As the inflammatory cascade takes time to develop, the peak inflammatory and vascular response is seen approximately 7 days after injury to nerve [38]. Because tranexamic acid has quick absorption (plasma concentration peak at 1 hour after intramuscular injection) and quick half-life, drug concentration will be gone before the peak inflammatory response develops [27]. Although we evaluated the most logical markers that might be affected by tranexamic acid on the sciatic nerve, we did not exhaust all possibilities and did not evaluate the effects of tranexamic acid on other structures, such as the muscles and joint implants. The inability to assess pain in the animal model also may have limited our assessment regarding the effect of tranexamic acid on nerve function. Despite good intentions, bias may have been introduced during surgical dissection, tranexamic acid application, or during histologic evaluation of each animal group.

In the rat model, we found that electrophysiologic parameters, including nerve conduction velocity and amplitude of the sciatic nerve, did not differ from those after application of tranexamic acid compared with saline controls at 4 days and at 1 month after surgery, with the numbers available. Distal latency, however, was slightly increased at 4 days but not at 1 month (Table 1), which may have been secondary to early neural irritation and which resolved without any effects at 1 month. With acute and chronic nerve compression injuries, nerve conduction velocity is slowed [28]. Our results showed no functional effects to the sciatic nerve or hind-limb muscle activity after topical application of tranexamic acid compared with the control group at 1 month, with the numbers available. As tranexamic acid has a short half-life (2-3 hours) and has been shown to cause EMG changes during local application in the rat spinal cord [13, 27], we hypothesized that tranexamic acid might have a transient effect or no effect on the sciatic nerve after local topical application. However, our results agree with our hypothesis. With one exception (distal latency in the $1 \mathrm{mg}$ tranexamic acid group at 4 days), with the numbers available, local application of tranexamic acid to the sciatic nerve had an effect on the parameters we studied in our model, which simulated surgical exposure of patients undergoing THA, at either 4 days or 1 month after application. Our findings likely reflect the selective effect of tranexamic acid on gammaaminobutyric acid (GABA) receptors, which are located in the central nervous system, not in the peripheral nervous system (sciatic nerve) [13].

We found no difference in macrophage recruitment at 4 days and at 1 month in tranexamic acid -treated sciatic nerve sections relative to controls, with the numbers available. This result differed from findings in a previous study in the rat [17], which showed that macrophage recruitment increased immediately in nerve sections that were acutely crushed compared with a gradual increase with long-term (months) chronic nerve compression. With trauma or surgery, injury to vascular endothelium results in exposure of collagen and release of tissue factors. The tissue factors and exposed collagen activate the extrinsic 
and intrinsic coagulation cascade, and in turn, plasminogen and the anticoagulation pathway. By competitively inhibiting the conversion of plasminogen to plasmin, tranexamic acid promotes the coagulation process. As tranexamic acid prevents degradation of clot formation, it is possible there is increased macrophage recruitment and an alteration of the blood-nerve barrier [17, 24]. Therefore, in our study, we found no change in macrophage recruitment to suggest an inflammatory process involving the sciatic nerve when treated with topical application of tranexamic acid.

When examining blood-nerve barrier integrity, our results also suggest that there is no 4-day or 1-month difference in the extravasation of Evans Blue albumin from the control nerve samples compared with the nerves treated with topical tranexamic acid, with the numbers available. In an animal study by Gray et al. [16], Evans Blue albumin extravasation increased in a sciatic nerve section at 2 and 4 weeks after compression injury. Omura et al. [25], in their study of acute nerve injury, reported that Evans Blue albumin leakage to the endoneurium was seen at 24 hours, peaking 3 to 7 days after injury, and returning to nearly normal levels at 21 days after injury. Similarly, Olsson [24] reported increased extravasation of Evans Blue albumin in an acutely crushed sciatic nerve rat model. Our results indicate that the blood-nerve barrier remains intact at 4 days and 1 month after topical administration of tranexamic acid, at which times an effect would be evident if there was to be one [16, 24, 25].

Topical application of tranexamic acid has shown good results in decreasing blood loss in patients during THA. Further randomized controlled studies are needed to find the optimal application dose, along with the timing and frequency of administration [15, 20]. Our study suggests that local topical administration of tranexamic acid does not affect sciatic nerve function in an in vivo animal model, with the numbers available. However, because our statistical power was low, these data should be considered hypothesis-generating pilot data for larger, more-definitive studies. Our findings may help support the safety of local topical use of tranexamic acid during THA.

\section{References}

1. Alshryda S, Mason J, Vaghela M, Sarda P, Nargol A, Maheswaran S, Tulloch C, Anand S, Logishetty R, Stothart B, Hungin AP. Topical (intra-articular) tranexamic acid reduces blood loss and transfusion rates following total knee replacement: a randomized controlled trial (TRANX-K). J Bone Joint Surg Am. 2013;95:1961-1968.

2. Alshryda S, Sarda P, Sukeik M, Nargol A, Blenkinsopp J, Mason JM. Tranexamic acid in total knee replacement: a systematic review and meta-analysis. J Bone Joint Surg Br. 2011;93:15771585 .
3. Astedt B. Clinical pharmacology of tranexamic acid. Scand J Gastroenterol Suppl. 1987;137:22-25

4. Bierbaum BE, Callaghan JJ, Galante JO, Rubash HE, Tooms RE, Welch RB. An analysis of blood management in patients having a total hip or knee arthroplasty. J Bone Joint Surg Am 1999;81:210.

5. Butala BP, Shah VR, Bhosale GP, Shah RB. Medication error: subarachnoid injection of tranexamic acid. Indian J Anaesth. 2012;56:168-170.

6. Camarasa MA, Ollé G, Serra-Prat M, Martin A, Sanchez M, Ricos P, Perez A, Opisso L. Efficacy of aminocaproic, tranexamic acids in the control of bleeding during total knee replacement: a randomized clinical trial. Br J Anaesth. 2006;96:576-582.

7. Capdevila X, Calvet Y, Biboulet P, Biron C, Rubenovitch J, d'Athis F. Aprotinin decreases blood loss and homologous transfusions in patients undergoing major orthopedic surgery. Anesthesiology. 1998;88:50-57.

8. Carson J, Grossman B, Kleinman S, Tinmouth AT, Marques MB, Fung MK, Holcomb JB, Illoh O, Kaplan LJ, Katz LM, Rao SV, Roback JD, Shander A, Tobian AA, Weinstein R, Swinton McLaughlin LG, Djulbegovic B; Clinical Transfusion Medicine Committee of the AABB. Red blood transfusion: a clinical practice guideline from the AABB*. Ann Intern Med. 2012; 157:49-58.

9. Chang CH, Chang Y, Chen DW, Ueng SW, Lee MS. Topical tranexamic acid reduces blood loss and transfusion rates associated with primary total hip arthroplasty. Clin Orthop Relat Res. 2014;472:1552-1557.

10. Chao T, Frump D, Lin M, Caiozzo VJ, Mozaffar T, Steward O, Gupta R. Matrix metalloproteinase 3 deletion preserves denervated motor endplates after traumatic nerve injury. Ann Neurol. 2013;73:210-223.

11. Charoencholvanich K, Siriwattanasakul P. Tranexamic acid reduces blood loss and blood transfusion after TKA: a prospective randomized controlled trial. Clin Orthop Relat Res. 2011;469:2874-2880.

12. Fryar CD, Gu Q, Ogden CL. Anthropometric reference data for children and adults: United States, 2007-2010. Vital Health Stat 11. $2012 ; 252: 1-48$.

13. Furtmuller R, Schlag M, Berger M, Hopf R, Huck S, Sieghart W, Redl H. Tranexamic acid, a widely used antifibrinolytic agent, causes convulsions by a gamma-aminobutyric acid(A) receptor antagonistic effect. J Pharmacol Exp Ther. 2002;301:168-173.

14. Gandhi R, Evans HM, Mahomed SR, Mahomed NN. Tranexamic acd and the reduction of blood loss in total knee and hip arthroplasty: a meta-analysis. BMC Res Notes. 2013;6:184.

15. Gilbody J, Dhotar HS, Perruccio AV, Davey JR. Topical tranexamic acid reduces tranfusion rates in total hip and knee arthroplasty. J Arthroplasty 2014;29:681-684.

16. Gray M, Palispis W, Popovich PG, Rooijen VN, Gupta R. Macrophage depletion alters the blood-nerve barrier without affecting Schwann cell function after neural injury. $J$ Neurosci Res. 2007;85:766-777.

17. Gupta R, Lin YM, Bui P, Chao T, Preston C, Mozaffar T. Macrophage recruitment follows pattern of inducible nitric oxide synthase expression in a model for carpal tunnel syndrome. J Neurotrauma. 2003;20:671-680.

18. Gybel M, Kristensen K, Roseva-Nielsen N. [Cardiac arrest caused by massive pulmonary embolism during treatment with tranexamic acid][in Danish]. Ugeskr Laeger. 2013;175:14261427.

19. Henry DA, Carless PA, Moxey AJ, O'Connell D, Stokes BJ, McClelland B, Laupacis A, Fergusson D. Anti-fibrinolytic use for minimising perioperative allogeneic blood transfusion. Cochrane Database Syst Rev. 2007;4:CD001886. 
20. Konig G, Hamlin BR, Waters JH. Topical tranexamic acid reduces blood loss and transfusion rates in total hip and total knee arthroplasty. J Arthroplasty. 2013;28:1473-1476.

21. Korte N, Schenk HC, Grothe C, Tipold A, Haastert-Talini K. Evaluation of periodic electrodiagnostic measurements to monitor motor recovery after different peripheral nerve lesions in the rat. Muscle Nerve. 2011;44:63-73.

22. Martin JG, Cassatt KB, Kincaid-Cinnamon KA, Westendorf DS, Garton AS, Lemke JH. Topical administration of tranexamic acid in primary total hip and total knee arthroplasty. $J$ Arthroplasty. 2014;29:889-894.

23. Mohseni K, Jafari A, Nobahar MR, Arami A. Polymyoclonus seizure resulting from accidental injection of tranexamic acid in spinal anesthesia. Anesth Analg. 2009;108:1984-1986.

24. Olsson Y. Studies on vascular permeability in peripheral nerves: I. Distribution of circulating fluorescent serum albumin in normal, crushed and sectioned rat sciatic nerve. Acta Neuropathol. 1966;7:1-15.

25. Omura K, Ohbayashi M, Sano M, Omura T, Hasegawa T, Nagano A. The recovery of blood-nerve barrier in crush nerve injury: a quantitative analysis utilizing immunohistochemistry. Brain Res. 2004;1001:13-21.

26. Panteli M, Papakostidis C, Dahabreh Z, Giannoudis PV. Topical tranexamic acid in total knee replacement: a systematic review and meta-analysis. Knee. 2013;20:300-309.

27. Puigdellivol E, Carral ME, Moreno J, Pla-Delfina JM, Jane F. Pharmacokinetics and absolute bioavailability of intramuscular tranexemic acid in man. Int J Clin Pharmacol Ther Toxicol. 1985;23:298-301.

28. Rydevik B, Nordborg C. Changes in nerve function and nerve fibre structure induced by acute, graded compression. J Neurol Neurosurg Psychiatry. 1980;43:1070-1082.

29. Salam A, King C, Orhan O, Mak V. The great deception: tranexamic acid and extensive pulmonary emboli. BMJ Case Rep. 2013;2013:pii bcr2012007808. doi:10.1136/bcr-2012-007808.
30. Schlag MG, Hopf R, Redl H. Convulsive seizures following subdural application of fibrin sealant containing tranexamic acid in a rat model. Neurosurgery. 2000;47:1463-1467.

31. Seo JG, Moon YW, Park SH, Kim SM, Ko KR. The comparative efficacies of intra-articular and IV tranexamic acid for reducing blood loss during total knee arthroplasty. Knee Surg Sports Traumatol Arthrosc. 2013;21:1869-1874.

32. Sepah YJ, Umer M, Ahmad T, Nasim F, Chaudhry MU, Umar M. Use of tranexamic acid is a cost effective method in preventing blood loss during and after total knee replacement. J Orthop Surg Res. 2011;6:22.

33. Tan J, Chen H, Liu Q, Chen C, Huang W. A meta-analysis of the effectiveness and safety of using tranexamic acid in primary unilateral total knee arthroplasty. J Surg Res. 2013;184:880-887.

34. U.S. Food and Drug Administration. NDA 19-281/S-030. Cyklokaprom $^{\mathbb{R}}$. Available at: http://www.accessdata.fda.gov/drugsatfda docs/label/2011/019281s030lbl.pdf. Accessed July 20, 2013.

35. Wong J, Abrishami A, El Beheiry H, Mahomed NN, Roderick Davey J, Gandhi R, Syed KA, Muhammad Ovais Hasan S, De Silva Y, Chung F. Topical application of tranexamic acid reduces postoperative blood loss in total knee arthroplasty: a randomized, controlled trial. J Bone Joint Surg Am. 2010;92:2503-2513.

36. Yamasaki S, Masuhara K, Fuji T. Tranexamic acid reduces postoperative blood loss in cementless total hip arthroplasty. J Bone Joint Surg Am. 2005;87:766-770.

37. Yang ZG, Chen WP, Wu LD. Effectiveness and safety of tranexamic acid in reducing blood loss in total knee arthroplasty: a meta-analysis. J Bone Joint Surg Am. 2012;94:1153-1159.

38. Ydens E, Cauwels A, Asselbergh B, Goethals S, Peeraer L, Lornet G, Almeida-Souza L, Van Ginderachter JA, Timmerman $\mathrm{V}$, Janssens S. Acute injury in the peripheral nervous system triggers an alternative macrophage response. J Neuroinflammation. 2012;9:176.

39. Zhang H, Chen J, Chen F, Que W. The effect of tranexamic acid on blood loss and use of blood products in total knee arthroplasty: a metaanalysis. Knee Surg Sports Traumatol Arthrosc. 2012;20:1742-1752. 